\title{
Numerical Analysis of the T-stub Beam-to- Column Hysteretic Behavior Affected by Beam Height
}

\author{
Li Zeshen ${ }^{1,}$, Su Ying ${ }^{2, b}$ and Zhang Keshi ${ }^{1, a}$ \\ ${ }^{1}$ Institute of Civil Engineering and Architecture, Guangxi University, Nanning, 530003, China. \\ ${ }^{2}$ Institute of Architectural Engineering, Hezhou University, Hezhou, 542800, China. \\ a 120198634@qq.com. \\ b544010279@qq.com.
}

Keywords: numerical simulation; T-stub connection; beam section height

Abstract. In this paper, we established a 3D nonlinear finite element analysis to high-strength bolt T-stub beam-to-column connections, Study and discussion the influence of beam section height to the hysteretic behavior, ductility and dissipation capacity of the beam-to-column connections . The results showed that: Appropriate additional of beam height can improved bearing capacity and dissipation capacity of the connections, but excessive high beam section height may limits the ductility of connections. At the same beam section height, appropriately increasing of the beam flange and Web plate thickness can improve ductility and dissipation capacity of the connections.

\section{Introduction}

When the United States Northridge earthquake in 1994 [1] and the Japan Kobe earthquake in1995 [2], Welded joint brittle failure accident occurs to many frame structure. After the earthquake, the researchers carried out extensive studied on the reason of the connections failure, and proposed a variety of new beam-to-column connections to improve the ductility of joints [3]. As it have a strong bearing capacity, excellent ductility performance, does not need welding, environmental protection and fast during the construction process, the T-stub Semi-rigid beam-to-column connections have a good application prospect of promotion[4]. Therefore, many related research of bearing capacity and seismic performance for T-stub Semi-rigid connections carried out by international scholars [5-7].As a ordinary T-stub connection, the upper and lower flange of the beam connected to the column through connecting plate, and there is no connection on the beam web. Therefore, mechanical properties of the nodes directly connected with the size of the beam section height. This paper established General FEM software ABAQUS finite element model to obtain load-displacement curves of the T-stub connections under cyclic loading, study the beam section height effect on mechanical properties of the connections, and proposes design recommendations.

\section{Model definition}

\section{A. Geometry Model}

In order to study the effect of beam section height, we designed two groups of seven connection specimens with different beam section height, the first set of beam flange and web is slightly larger than the second groups. There are six specimens of the column section size $300 * 300 * 10 * 15$, T-stub connector section size are $250 * 200 * 10 * 15.16$ M20 friction-type high-strength bolt was used. Specimen parameters shown in Table1.

Table 1 Beam Height

\begin{tabular}{|c|l|l|l|l|l|l|}
\hline Beam section size & \multicolumn{3}{|l|}{$\left(\mathbf{H}^{* 200} \mathbf{2} * \mathbf{1 4}\right)$} & \multicolumn{3}{c|}{$(\mathbf{H} * \mathbf{2 0 0} \mathbf{8} * \mathbf{1 2})$} \\
\hline Specimens & HB1 & HB2 & HB3 & HB4 & HB5 & HB6 \\
\hline $\boldsymbol{H}$ & 300 & 350 & 400 & 294 & 350 & 400 \\
\hline
\end{tabular}




\section{B. Finite Element Model}

The T-stub connections model consists of steel beams, steel columns, T-connections and high strength bolt friction, used solid modeling by finite element analysis software ABAQUS. Three dimensional hexahedral non-coordination models linear unit element (C3D8I) is adopted for T-stud steel beams, columns and connections. The structured meshing technique (sweep) is assigned to have a proper element shape, the stress concentration area such as T-stud connections and bolts made of artificial mesh refinement[8].
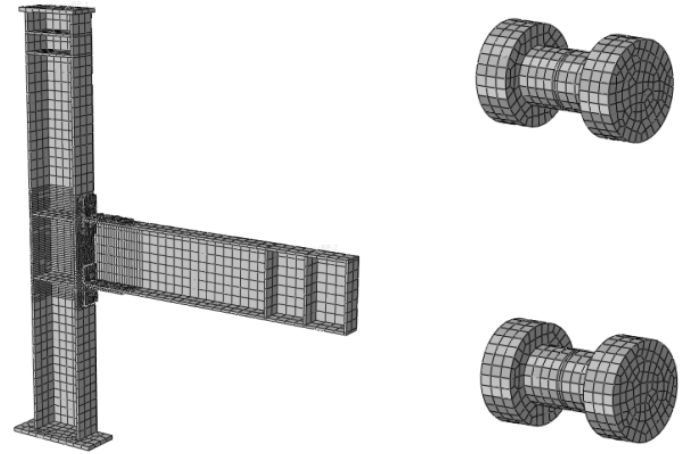

Fig.1 T-stub connection Modle

\section{Material Constitutive Modeling}

Stress-strain relation of steel as shown in Fig.2, used three lines linear relationship, and the material stress-strain relationship of high-strength bolts as shown in Fig.3. Mises yield criterion and isotropic hardening model was available. Full Newton method was used to solving nonlinear equation group. Two material parameter values shown in table 2:

Table 2 material parameters of high strength bolts

\begin{tabular}{|c|c|c|c|c|c|}
\hline item & $E_{s}$ & $\sigma_{0}[\mathrm{Mpa}]$ & $\mathbf{v}$ & $\sigma_{u}$ & $\varepsilon_{u}$ \\
\hline steel & 206000 & 263.2 & 0.3 & 444.98 & 0.146 \\
\hline bolt & 187500 & 1063.9 & 0.3 & 1009.65 & 0.059 \\
\hline
\end{tabular}

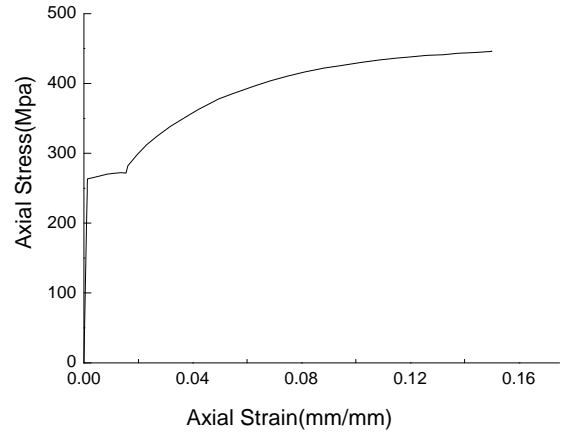

Fig.2 Steel stress-strain curve

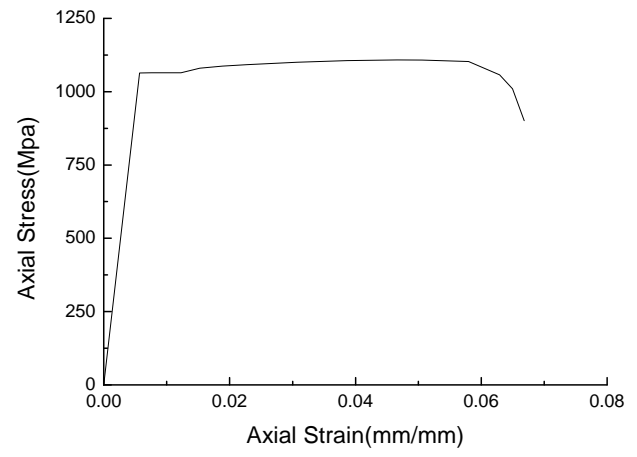

Fig.3 High strength bolt stress - strain curve

\section{A. Boundary conditions and Loading models}

Match the boundary conditions of the model to practical boundary conditions of joints, hinged joint was set on the top of the column, and the vertical axis was pressured. Axial compression ratio is 0.2, fixed the bottom of the column. In order to accelerate calculation, just modeling half of the actual structure, and applying the symmetry constraint in the symmetric plane. Imposed 155KN M20 bolt pre-tighten force on the parts of high-strength screw bolt connections. Cyclic loading of uniaxial loading yield displacements was applied at the beam end until the component was completely destroyed. Each imposed displacement cycled one time. 


\section{Results of numerical analysis}

\section{A. Load-Displacement Hysteretic Curve}

The first group (HB3、HB2、HB1) beam height decreases, and the second group (HB4、HB5、 HB6) beam height increase. The load-displacement hysteretic curve was showed in Fig. 4 , the figure shows : the joints hysteresis curve was submitted reversed's shape, indicating the bolts slid gradually during the stress process; the relatively smaller of beam section height, the joints hysteresis curve was more full; the bearing capacity decreases With the decrease of the beam section height.

Three groups of specimens which have different beam flange. Include of HB1 and HB4、HB2 and HB5、HB3 and HB6. Figure 4 shows that HB1、HB2、HB3 which the thickness of beam flange and web is relatively large than HB4、HB5、HB6 have greater ultimate bearing capacity, limit displacement. Therefore, appropriate increase the thickness of the beam flange and web can be to some extent improved carrying capacity and energy dissipation capacity of the joints.
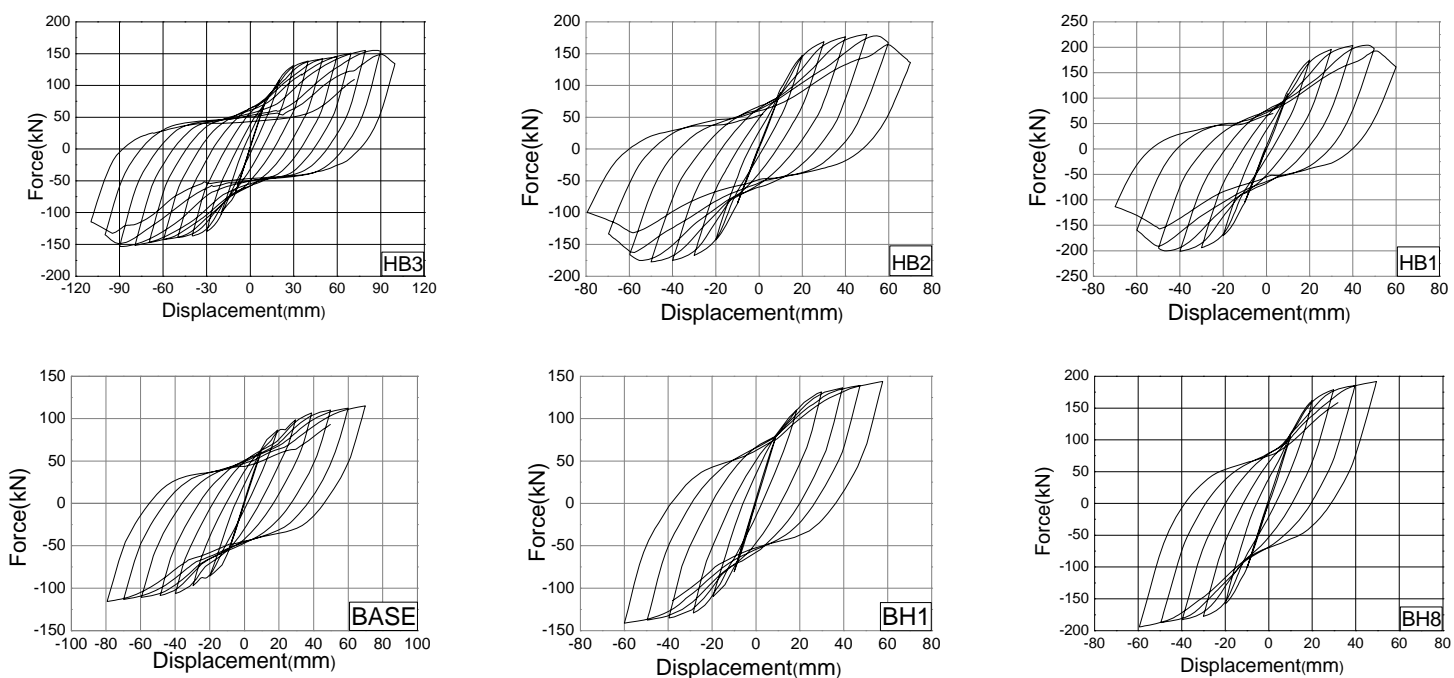

Fig.4 Hysteretic response of $\mathrm{BH}$

\section{B. Ductility and Seismic Performance}

Beam height of Specimen HB3, HB2, HB1, BH decreases, and Specimen BH2, HB4, HB6 increase. Fig.5 shows that ductility coefficient of the joints reduced with beam section height increases, that is, ductility performance of joints reduced with beam section height increases. We consider it is the higher steel sections have larger stiffness, so deformation capacity is not good, also lack of connection between beam web and column lead to unstability of joints.

Figure 5 also shows that the larger thickness of the beam flange and web would have a better ductility coefficient and energy dissipation coefficients. Therefore, when control beams linear stiffness under the premise of 0.4 to 0.6 , appropriately increase the thickness of the beam flange and web can improve the ductility and seismic performance of nodes.

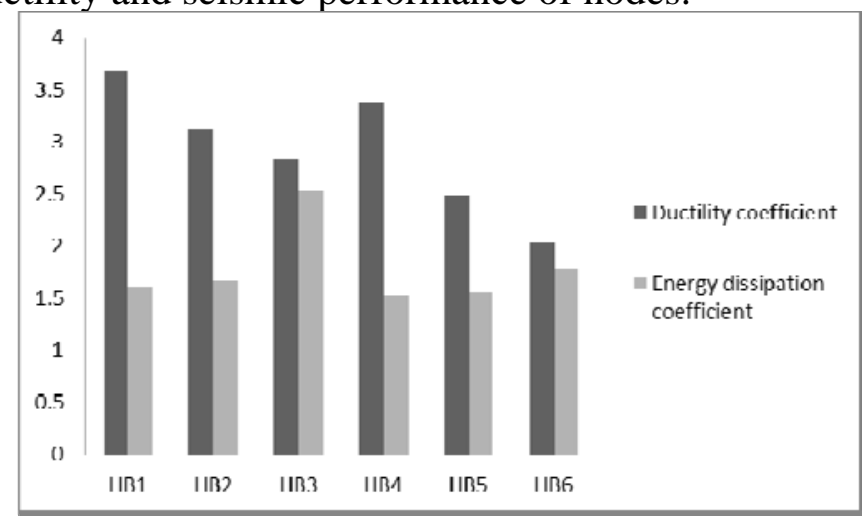

Fig.5 Seismic Performance of BH 


\section{Conclusion}

In this paper, T-stub semi-rigid connections model was established by the finite element software ABAQUS, and simulated the response of joins under different beam section height under low reversed cyclic load. The calculation results show that: bearing capacity, energy consumption coefficients of T-stub connections increase with the increase of beam section height; the excessive beam section height will lead to poor ductility; when control beams linear stiffness under the premise of 0.4 to 0.6 , and at the same beam section height, appropriately increase the thickness of the beam flange and web can improve the ductility and seismic performance of nodes.

\section{References}

[1]. Nakashima M,Inoue K,Tada M. Classification of damage to steel buildings observed in the 1995 Hyogoken-Nanbu earthquake. Engineering Structures.1998,20(4):271-281

[2]. AISC, Special Task Committee on the Northridge Earthquake. American Institute of Steel Construction, Chicago,1994

[3]. Bjorhovde R., Colson, A. and Brozzetti, J., Classification System for Beam-to-column Connections, Journal of Structural Engineering, ASCE, 1990, 116(11):3059-3076

[4]. Swanson JA. Characterization of the strength, stiffness, and ductility behavior of T-stub connections. Ph.D. thesis. Atlanta (GA): Georgia Institute of Technology; 1999.

[5]. Smallidge JM. Behavior of bolted beam-to-column T-stub connections under cyclic loading.M.S.thesis. Atlanta(GA):Georgia Institute of Technology;1999.

[6]. Egor P.Popov,Shakzod M. Bolted large seismic beam-to-column connection Part 1:experimental study.Engineering Structures,24(2002)1523-1534.

[7]. Latour,M,Rizzano,G. Experimental Behavior and Mechanical Modeling of Dissipative T-Stub Connections. J of Structural Engineering, 138 (2), 2012,170-182.

[8]. ABAQUS.Analysis user's manual I_V.Version 6.10. USA: ABAQUS, Inc.,Dassaykt ststense; 2010. 